\title{
"Increased communication as first response in stalking victims and why stalking laws protect perpetrators "
}

\author{
Pardis Tabaee Damavandi
}

Stalking or the crime of "persecutory acts" otherwise previously known as "mobbing" is found both in common law and in some civil law jurisdictions however these laws are not very well-defined and are often wrong or not written properly.

The purpose of this law would be to prevent abuse, even if the stalking law is often used to abuse, as the stalker pretends to be the victim and some stalkers have even gotten to the point of inventing stalking victims to "confuse" trials. In the latter case, the case was being dismissed, and the stalker or more correctly stalkers walked away, able to repeat the same crimes against different victims.

Firstly, Public Administration (PA) is the only way someone could stalk, as they have the means to do so, the means are often prosecutors in some cases and police forces in other cases or both.

Secondly, stalking is not the crime of domestic violence, but victims are unknown and may side with domestic or workplace abusers. Abuse involves financial or physical abuse mainly. Physical abuse involves the threat of physical violence or loss as much as the violence itself, and financial abuse involves as much as a threat to financial loss resulting in physical loss as much as actual financial loss. Even though other forms of abuse exist, none of them really results in anxiety and loss of health or damages.

Nevertheless, the first response to stalking in the real victim which differentiates them from false victims and perpetrators is anxiety and thus sickness, whereby there is an actual loss and damage and that makes the sadistic stalker "proud of their achievement", due to the psychopathy condition which is unintelligible. Stalkers are by definition psychopathic and psychopaths have been forced into our society, even if we ought to be safe. Some forms of cheating could be considered stalking too particularly where there's been a loss of health and hence the physical loss due to it, but even financial, particularly when a sexually transmitted disease is involved. The fact that cheating laws have been removed from the legal codes means that stalking laws should be removed too allowing for normal criminal laws and procedures being considered which are already enough to actually prevent stalking. Some stalking laws further harm the victim, for instance, increased communication and keeping receipts of failed PA duties is a way for stalking victims to safeguard themselves but stalking laws are often thwarted regardless of the ethical implications and they sometimes state that communication is a crime. That is not the case as communication is forced by the stalker due to continuous threats that are unjustified since the stalker is a third party acting on behalf of an abuser, the abuser who violated laws and stole public funds will blame random bystander victims and work on the fellow stalker's prejudice, psychopathy and malignant narcissism. Some even condemn normal behaviours as stalking which have no 
logical outcomes, an example is the institute of donations. The actual stalking act is that of abuse, and stalking law supposedly was made for its prevention.

Ultimately, the stalker's induced loss must be unjustified too. For instance, evading taxes and accusing someone of stalking is wrong, however accusing someone of evading taxes where the duty of administration failed is a form of extortion and thus could be considered stalking too. As such, the most common anxiety illnesses involve gynaecological tumours, inflammations and other problems due to epinephrine release in the pelvic region. Stalking laws may prevent some corruption ideally, but if written wrongly as is the case in common law or mixed law jurisdictions they can really be harmful. It is thus better not to have them and replace them with other laws that are typical of crime. Some jurisdictions even allow stalking as a civil case, whereby the stalker could pay for damages, but again civil damages are initial, with personal injury, then a further boundary is crossed, in that case the area of crime becomes of fraud, privacy violation or of calumny, in some cases of violence that result in injury and sometimes death too, but it is aggravated to cover other crimes which again is already punished in criminal law.

All organised criminals will use stalking laws to justify organised crime. Thus, it is better not to have stalking laws like in some civil code countries, than to have them and having them could prevent real justice instead of granting it. Stalking is transnational too, thus a stalking law would have to take all these elements into account to exist. If the case is dismissed and the stalker gets away with it, the stalker will continue to recruit other stalkers do his or her job, at least in countries where stalkers are protected by these laws. As a result, legal harmonisation is good, but to some extent. If a law is poor then it has to be discarded. Unfortunately, it is this way and sometimes there can be incredible biases too whereby criminals are protected and victims suffer in silence.

No conflicts of interest to disclose 